\title{
El nuevo reto digital se llama creatividad
}

\author{
Laura Llopis \\ Directora de Estrategia y Desarrollo \\ de Negocio de Weaddyou
}

\section{Referencia de este artículo}

Llopis, Laura (2019). El nuevo reto digital se llama creatividad. adComunica. Revista Científica de Estrategias, Tendencias e Innovación en Comunicación, (18). 301304. DOI: http://dx.doi.org/10.6035/2174-0992.2018.16.15

No dejamos de escuchar que las marcas tienen nuevos retos. Estos pasan por ser culturalmente visibles, es decir, ser relevantes en un entorno donde nunca hubo tanto ruido y donde nunca fue tan fácil ignorarlo. Además, las marcas deben ser esenciales para el consumidor, pues hay tantas opciones donde elegir que, si éstas no resuelven una verdadera necesidad, no serán consideradas. Y deben crear las estructuras mentales correctas para asegurar que cuando la necesidad exista, el consumidor las tenga en su abanico de posibilidades y las escoja frente a otras.

Pero no solo eso, también se exige a las marcas que estén comprometidas con una causa interesante (lo que ya llamamos marcas con propósito) para su público porque, puestos a consumir, lo haremos a través de aquellas que nos hagan sentir que ejercemos un consumo socialmente responsable. Por eso se ha pasado de medir el top of mind a aspirar al top of heart, es decir, las marcas deben tocar el corazón de las personas si quieren tener éxito.

Es una evolución natural. Cuando las opciones se multiplican, cuando el acceso a la información de estas opciones es relativamente sencillo, cuando puedes comprar haciendo un solo click y asegurarte de que esa compra estará mañana en tu casa, 
los consumidores damos un salto más y pedimos que esa compra nos haga sentir bien, felices, comprometidos con una causa. Y no solo eso, también pedimos que toda la información de la marca nos llegue a través de una historia que nos entretenga (contenidos), que sea lo más personalizada posible (one to one) y, por supuesto, que podamos consumirla inmediatamente y a través de cualquier dispositivo (pantallas).

Porque nos comunicamos a través de pantallas (eso es el digital) y estas están siempre en nuestras manos. Según una encuesta de hábitos de consumo de YouGov, el $49 \%$ de los españoles dice chequear entre diez y cincuenta veces su móvil diariamente, mientras que un $26 \%$ se atreve a confesar que lo hace más de cincuenta veces al día. Otra encuesta de Deloitte (Encuesta Mundial de Consumidores Móviles de 2018) afirma que los estadounidenses revisan sus smartphones un promedio de 52 veces al día, mientras que el año anterior la cifra era de 47 veces por día. Más allá del número de veces, lo que parece claro es que se chequea el teléfono en busca de estímulos constantes, porque ahora el prime time es all time.

Ante este panorama, los profesionales de la comunicación que trabajamos en agencias de publicidad tenemos que hacer lo que siempre hemos hecho: ser creativos para contar historias, porque la publicidad va de eso, de historias que nos conectan con las marcas, pero también entre nosotros. Lo que ha aportado el digital es que estas historias se resuelven en un contexto algo diferente al de hace unos años. Porque la tecnología ha cambiado y con ella nuestro modo de comunicarnos. Ahora no solo queremos que las historias nos lleguen rápido y nos entretengan, queremos que sean lo suficientemente relevantes para compartirlas porque nunca fue tan fácil como hoy compartir el contenido. Y lo que compartimos habla de nosotros, nos reafirma en lo que somos y nos ayuda a mostrárselo a los demás.

En la era digital (y en la anterior también), la gente odia la mala publicidad, porque se cuela en nuestras pantallas, nos interrumpe y nos hace perder un tiempo que podríamos usar en consumir miles de contenidos interesantes. En cambio, si el mensaje nos gusta, no nos importa que la marca esté en el centro. Los chats de WhatsApp han pasado a ser un nuevo KPI en las mediciones de la eficacia.

Este contexto digital hace que las ideas que creamos se midan por raseros diferentes a los que se usaban antes de que las tecnologías lo invadieran todo. Ahora los profesionales de la comunicación tenemos que conseguir crear ideas que inspiren a los consumidores, que sean capaces de generar conversaciones, que produzcan un impacto positivo en las audiencias y que, además, generen un cambio. Además, esas ideas deben ser lo más personalizadas posible, porque queremos que las marcas nos hablen a nosotros, en primera persona.

Para conseguir este tipo de ideas y llegar a los consumidores, el uso de los datos se ha vuelto fundamental. Los datos nos permiten entender lo que hace la gente, lo que quiere, lo que necesita. Pero no el dato en sí mismo. Hoy, probablemente el mayor reto de las agencias y de sus profesionales, es ordenar esos datos y encontrar aquel o aquellos que son relevantes para nuestro trabajo, aquellos capaces de 
conectarnos realmente con las personas y ofrecerles algo significativo para ellas. Los datos nos muestran la realidad, pero nosotros tenemos que encontrar, entre todos ellos, los insights que nos permitan conectar a las marcas con las personas. Porque este negocio va de personas y la tecnología solo es un modo de acceder a ellas.

Además de esto, los profesionales de hoy tenemos que entender el digital como un medio más porque nos comunicamos a través de él. Todo es digital. Ya no tiene sentido diferenciar entre digital y otros medios. De hecho, todos los medios se conectan digitalmente desde el momento en que recibimos la información en distintas pantallas a lo largo del día. El digital en comunicación no deja de ser más que un reflejo de la sociedad, que cambia cada día los hábitos de consumo en función de lo que nos permiten las tecnologías. El reto pasa por integrar ese pensamiento digital, que todos tenemos en cuanto que somos consumidores, en los procesos de creación de la agencia. Y en ser conscientes de que, una vez la idea salga, volverá a través de diferentes interacciones con el público, que tiene más poder que nunca para opinar sobre ella, para interaccionar con ella, para hacerla grande o para ignorarla. 
